\title{
CLAUSTROFOBIA CULTURAL E \\ EVOCAÇÃO LÍRICA EM LOS RÍOS PROFUNDOS
}

\author{
Edina Boniatti \\ Mestre em Linguagem e Sociedade pela Universidade Estadual do Oeste do Paraná \\ (UNIOESTE) \\ edina21boniatti@gmail.com \\ Valdeci Batista de Melo Oliveira \\ Doutora em Letras pela Universidade de São Paulo (USP) \\ Professora Associada da Universidade Estadual do Oeste do Paraná (UNIOESTE) \\ valzinha.mello@hotmail.com
}

\section{RESUMO}

Neste artigo analisa-se a relação do protagonista Ernesto, da obra Los Ríos Profundos (1993), com o espaço do internato, onde o mesmo se sente constrangido e onde aprendera os ícones da cultura do colonizador: a história, a língua e os valores carreados por elas. Esse espaço claustrofóbico impulsiona Ernesto a reconstruir, comparativamente, por meio da memória, as experiências empíricas da convivência com os indígenas. Assim, o personagem resgata elementos que permitem avaliar criticamente a sociedade peruana, bem como fazer sua opção identitária.

Palavras-chave: espaço, memória, natureza, opção identitária.

\section{ABSTRACT}

This paper aims to analyze the protagonist's relation, Ernesto, from Los Ríos Profundos (Deep Rivers) (1993), within the boarding school, in which he feels intolerant and where he learnt the icons of the colonist's culture: history, culture and language. This claustrophobic space pushes Ernesto to rebuild, comparatively, throughout his memory, empirical experiences of the living with the indigenous people, and, this way, to retrieve elements that allow him to evaluate the Peruvian society critically and to make his identity choice.

Keywords: space, memory, nature, identity choice. 
Debía ser como el gran río: cruzar la tierra, cortar las rocas, pasar indetenible y tranquilo, entre los bosques y montañas; y entrar al mar, acompañado por un gran pueblo de aves que cantarían desde la altura. (José María Arguedas, Los ríos profundos)

Em Abancay, cidade pequena e silenciosa, situada no centro-sul do Peru, às margens do rio Mariño, afluente do Pachachaca, termina a peregrinação de Ernesto, narrador protagonista de Los rios profundos de José María Arguedas. O pai o trouxera até ali para que, no internato, completasse seus estudos. Desejava, pois, que o filho tivesse, preferencialmente, uma vida diferente da sua, já que como um errante advogado de províncias buscava incessantemente uma localidade promissora, a fim de fixar residência e conquistar estabilidade profissional. Desse modo, diza o menino:

Y ahora estás en un internado de un colegio religioso. (...)iPero estás en tu colegio! ¡Estás en tu lugar verdadero! Y nadie te moverá hasta que termines, hasta que vayas a La Universidad. iSólo que nunca, que jamás serás abogado! Para los grandes males basta conmigo (ARGUEDAS, 1993, p. 29).

Assim, Ernesto, que, dos 12 aos 14 anos de idade, percorre mais de duzentos povoados da região sul da serra andina, conhece modos de vida diversos, esquadrinha prados e planícies, contempla, com o olhar moldado no seio da cultura indígena, a natureza e valoriza o quéchua como idioma preferencial. O personagem vê-se confinado em um espaço em que a cultura e a religião brancas são tidas como indicativos de distinção e superioridade. Nesse ambiente, que ele sente claustrofóbico e intolerante, torna-se mais evidente o preconceito no que refere à cultura andina. Lateja na alma do menino a conflitiva relação entre as culturas branca e indígena da sociedade peruana. 
Em Los rios profundos (1993), obra carregada de um tom melancólico, nostálgico e confessional, observa-se que viver no espaço do internato foi fundamental para que, ao aprender sobre a história, a língua, a cultura do colonizador, Ernesto pudesse compará-las com as experiências empíricas da convivência com os indígenas e, assim, reunisse em sua história-memória elementos que permitissem a ele avaliar criticamente a sociedade peruana e fazer sua opção identitária.

É, pois, a contraposição paralelística entre o espaço opressivo do internato e os espaços das imagens infantis armazenadas na memória que animam a memória do menino que garantem à obra uma dolorosa indignação. Dela resulta a escrita mesclada de tonalidade de denúncia de quem se recusa a aceitar a crueza das agressões sofridas pelo povo e pela cultura indígena. O narrador faz questão de reafirmar que a violência material e simbólica não pode ser vista como um processo natural do desenvolvimento socioeconômico e cultural de seu país.

Na tese de doutorado, Um diálogo entre "Balún Canán" e "Los rios profundos" (2008), a pesquisadora Tereza Cristina Filippo assevera que as preocupações em não permitir a anulação do lastro cultural andino e em denunciar os abusos e desmandos contra os povos indígenas sempre estiveram presentes na vida prática de José María Arguedas. Sendo assim, não há como separar a sua escrita literária de sua história pessoal, visto que tanto a vida biográfica quanto as marcas etnográficas de suas vivências e os sentimentos que delas emanam se espalham por toda a tessitura de sua narrativa:

Arguedas tinha, entranhada na alma, a marca da cosmovisão andina e a marca do preconceito que sufoca a vida da comunidade nativa. Conheceu de perto a cultura e a religião brancas. Obteve mérito entre elas, mas nunca conseguiu perder de vista as marcas indígenas adquiridas. A situação errante do índio que, ao perder suas terras, 
sua origem, seus laços com seu ayllu, e também sua identidade, foi conhecida de perto por Arguedas, que teve moldada sua natureza de eterno forasteiro entre dois mundos nestes tempos em que viajava com seu pai. Mal começava a lançar raízes num local já era hora de mudar. Foi sempre um migrante entre dois mundos antagônicos (FILIPPO, 2008, p. 17).

Logo, com memórias enriquecedoras da consciência imaginativa, as experiências da vida empírica modulam e amplificam a obra literária arguediana e manipulam a organização verbal do sentido que deixam transparecer a ligação biográfica e afetiva que plasmam o romance. Elas desnudam seu tempo, seu espaço, sua história individual e coletiva, sua posição frente às ideologias dominantes, às tradições culturais e sociohistóricas, alcançando as alturas de uma figuração narrativa marcadas de potencialidades literárias. Desse modo, levando em conta a afetividade do discurso que se transparece nas páginas da obra em estudo, não podemos denominá-la apenas como uma composição autobiográfica, mas especialmente memorialista. Em Dicionário de termos literários (2013), observa Massaud Moisés:

Movendo-se no espaço ocupado pela autobiografia, pelo diário e pelas confissões, as memórias distinguem-se por constituir um relato na primeira pessoa do singular que visa à reconstrução do passado, com base nas ocorrências e nos sentimentos gravados na memória, segundo as duas formas (a voluntária e a espontânea) que pode assumir.

Sendo acessório o pormenor cronológico, o andamento narrativo decorre com a apreensão de experiências julgadas relevantes por parte do autor, não apenas como testemunho de uma existência marcada por episódios pitorescos e incomuns, mas também das impressões que os outros lhe deixaram na memória. A veracidade que possam ter é menos documental que vivencial: o subjetivismo, congenial às modalidades autobiográficas vizinhas, alcança nesse caso suma intensidade, 
aproximando-se ainda mais do terreno ocupado pela narrativa ficcional ou pelo lirismo (MOISÉS, 2013, p. 289).

Esse lirismo emanado da memória torna-se perceptível já no título metafórico da obra por meio do qual Arguedas evoca a força das raízes culturais andinas. Tal qual o rio que nasce, nas cordilheiras, plácido, débil e raso, tornando-se intenso, caudaloso e profundo, a cultura indígena, por vezes ignorada e obscurecida, está fortemente arraigada no imaginário das populações peruanas e é o alicerce de sua sustentação histórico-cultural. Submersa nos entremeios cotidianos, em que a cultura europeia busca escamotear e sobrepor sua vivacidade, as raízes ancestrais da cultura, construindo e sendo construção do imaginário popular, nutrem a crônica diária das vivências e se configuram como marca simbólica da luta identitária de um povo subjugado e torturado pelo colonizador branco europeu.

Arguedas abre o capítulo Puente sobre el mundo, em que apresenta a constituição de espaços de alguns bairros de Abancay e espaços e personagens do colégio interno, com a epígrafe: ¡Pachachaca! Puente sobre el mundo, significa este nombre. Vê-se que aqui há a metaforização da ponte sobre o mundo: esta aproxima as duas culturas sentidas pelo menino como o substrato simbólico que permitirá a travessia de uma margem à outra; passagem alegórica que pode conduzi-lo ao extravasamento das emoções; levá-lo, individualmente, à transposição da sua condição de opressão, de solidão e de angústia sentida no internato e, coletivamente, à remissão no que se refere às práticas de violência do colonizador contra a vida material e cultural do indígena.

A imagem lírica do rio parecendo representar um desejo de que substitua a rudeza das imagens conflitantes, agressivas e cruéis que se desenham ao longo da apresentação do cenário da cidade e do internato também encerra esse capítulo. Nesse momento 
narrativo, o rio, também protagonista da histórica, ganha ainda maior densidade simbólica e comunica-se com as análises bachelardianas, na obra A Água e os Sonhos: Ensaio sobre a Imaginação da Matéria (2002).

Para Bachelard, as projeções que procedem da água na literatura revelam emanações psíquicas de um eu nutrido por uma força imaginativa que adquire uma significação muito maior e mais pertinente do que as imagens que a figuração das águas possam deixar, em um primeiro momento, transparecer no narrador. A água é, pois, aquela que abranda a aridez, devolvendo a fertilidade e a possibilidade do pulsar da vida. E é ainda "objeto de uma das maiores valorizações do pensamento humano: a valorização da pureza. Que seria da ideia depureza sem a imagem de uma água límpida e cristalina, sem esse belo pleonasmo que nos fala de uma água pura?" (BACHELARD, 2002, p. 15).

Quando modulada pela fluidez do rio, a água percorre imensos trajetos até chegar ao mar, desfecho de seu destino. Assim, desvenda percursos desconhecidos e assume um papel ativo na transformação das formas daquilo que encontra pelo caminho; ao passar das correntezas vivificam-se, purificam-se e renovam-se fauna e flora. A vida reluz! Logo, movido pela magia simbólica da água, Ernesto - mesmo quando passou meses desolado no vale profundo de Los Molinos, porque seu pai estava sendo perseguido - sempre acreditou nas torrentes libertadoras do rio que a novos mundos poderiam conduzi-lo:

Pero aun allí, en aquel Valle frío, que sepultaba a sus habitantes; solo, bajo el cuidado de un indio viejo, cansado y casi ciego, no perdí la esperanza. Los peces de los remansos, el gran sol que cruzaba rápidamente el cielo, los jilgueros que rondaban los patios donde se tendía el trigo, y los molinos que empujaban lerdamente la harina; el sudario, cubierto de polvo, de las cruces que clavan en las paredes de los molinos; el río, aun así enmarañado y bárbaro, me dieron aliento (ARGUEDAS, 1993, p. 49). 
Percebe-se aqui a descrição de um apego telúrico que mescla elementos físicos da paisagem com elementos da memória marcada pela nostalgia da recordação de um alento que o frio vale sustentou. O narrador demonstra notar que se a libertação na vida material e política não está próxima, mas a libertação pelo reconto das memórias está ao alcance de sua escrita e figuração e, com ela, busca fabular uma projeção alegórica libertadora. Assim, aos domingos, o menino afasta-se do colégio interno e percorre os campos, por horas, até chegar ao Pachachaca. O anseio que o acompanha é o de fuga do ambiente hostil do espaço físico que o cerca e sufoca juntamente com os ícones da cultura do colonizador. Assim, sentindo-se sufocado pelas altas paredes desnudas e frias, desolado e solitário, sai à procura da "maternal imagen del mundo" (ARGUEDAS, 1993, p. 49). Como apreensão dos códigos culturais indígenas, a natureza mãe possuía, para Ernesto, um poder curador, abrandando-Ihe a carência materna, consolando-lhe da ausência do pai e dos amigos índios que povoam suas lembranças e seu imaginário e, por fim, inundando-lhe o espírito de uma heroica fortaleza que lhe permite suportar o retorno ao colégio, a convivência conflituosa com os símbolos religiosos e culturais dos padres, e com as ações comportamentais dos colegas.

A veces podía llegar al río, tras varias horas de andar. Llegaba a él cuando más abrumado y doliente me sentía. Lo contemplaba, de pie sobre el releje del gran puente, apoyándome en una de las cruces de piedra que hay clavadas en lo alto de la columna central.

El río, el Pachachaca temido, aparece en un recodo liso, por la base de un precipicio, donde no crecen sino enredaderas de flor azul. En ese precipicio suelen descansar los grandes loros viajeros; se prenden de las enredaderas y llaman a gritos desde la altura.

Hacia el este, el río baja en corriente tranquila, lenta y temblorosa; las grandes ramas de chacha como que rozan la superficie de sus aguas se arrastran y vuelven 
violentamente, al desprenderse de la corriente. Parece un río de acero líquido, azul y sonriente, a pesar de su solemnidad y de su hondura. Un viento casi frío cubre la cima del puente.

El puente del Pachachaca fue construido por los españoles. Tiene dos ojos altos, sostenidos por bases de cal y canto, tan poderosos como el río. Los contrafuertes que canalizan las aguas están prendidos en las rocas, y obligan el río a marchar bullendo, doblándose en corrientes forzadas. Sobre las columnas de los arcos, el río choca y se parte; se eleva el agua lamiendo el muro, pretendiendo escalarlo, y se lanza luego en los ojos del puente. Al atardecer, el agua que salta de las columnas, forma arcoiris fugaces que giran con el viento. (ARGUEDAS, 1993, p. 50).

Nota-se que o lirismo pungente e elegíaco marca o tom dessa descrição do rio em que estão presentes elementos das duas culturas que a ele se ligam intimamente: a ponte do colonizador e os velhos amigos índios. Ernesto enfatiza que desconhece se a intensidade do seu amor é maior para com o rio ou para com a ponte. E ambos os elementos estão vinculados ao movimento, à passagem de uma margem a outra, ao imergir nos fossos da memória "em busca do tempo perdido", numa perspectiva semelhante à de Proust, como afirma Massaud Moisés acerca da literatura memorialista. Entretanto, o movimento das águas do rio e a possibilidade de chegar até a outra margem por meio da ponte revelam que esse mergulho no passado não traz o posicionamento passivo de um inócuo recordar, mas sim um desejo de restauração, modulado por um contorno que, embora parta da esfera pessoal, traz a intencionalidade de alcançar a esfera coletiva.

$\mathrm{Na}$ interlocução fantasmática que estabelece com Maywa, Demetrio Pumaylly e Pedro Kokchi - seus queridos e velhos espectros indígenas, animadores da sua memória e afetos, e com quem o escritor Arguedas conviveu na vida real da fazenda do tio, José Perea, em Viseca - o menino Ernesto reconstrói a memória histórico-social que moldara, 
conscientemente e/ou inconscientemente, as particularidades de sua personalidade, bem como a perspectiva do olhar de autenticidade de sentimentos que despontam das páginas narrativas, quando o menino se volta à recordação predicativa do rio, relacionando-a à cosmovisão adquirida por meio das conversações, experiências e vivências que partilhara com seus protetores e amigos índios. É seguindo essa cosmovisão das ancestrais raízes culturais andinas que Ernesto afirma: "iSí! Había que ser como ese río imperturbable y cristalino, como sus aguas vencedoras. ¡Como tú, río Pachachaca! ¡Hermoso caballo de crin brillante, indetenible y permanente, que marcha por el más profundo camino terrestre!" (ARGUEDAS, 1993, p. 51).

A coerência desse anseio explica-se já na abertura do capítulo Puente sobre el mundo por meio da relação antagônica estabelecida entre o título e a epígrafe líricos e o desamparo e a miséria figurados na situação inicial em que ocorre a descrição daquele que Ernesto apresenta como o único bairro alegre da cidade de Abancay, Huanupata. Ali vivem peões, carregadores, soldados, empregados de lojas e pessoas humildes de modo geral. Além de ser o único bairro em que é possível encontrar-se chicherías, é também espaço de passagem para aqueles que cruzam pela cidade, pois é nesse bairro onde há instalações para o pouso detropeiros, viajantes mestiços, entre outros.

Observa-se que, para Mark Augé (2005), os locais de diversão e passagem não são lugares antropológicos que marcam a construção identitária de um homem, mas podem ser denominados como "não-lugares", espaços não relacionais, não identitários e nem históricos. Locais públicos em que se configuram espaços do efêmero, nos quais os sujeitos fantasiam e representam realidades que, por vezes, não são parte de suas vivências. Assim, podem ser desarraigados de sua personalidade, numa ambientação em 
que o entretenimento tende a levar ao esvaziamento das idiossincrasias pessoais pela força do consumo unificador.

Todavia, é imprescindível assinalar que, em Los ríos profundos, há uma inversão no que concernem os lugares antropológicos e os não antropológicos da perspectiva de Augé. Dessa maneira, na obra, as chicherías - locais de prostituição e diversão frequentados, especialmente, por forasteiros, mestiços e índios - são, para Ernesto, os únicos ambientes, em Abancay, em que ele encontra vestígios dos lugares antropológicos que constituíram o seu eu. Desse modo, sua frequentação a esses ambientes ocorre exatamente pela possibilidade de encontrar os indivíduos e elementos culturais que figuram em sua história como marcos identitários: os índios empregados das fazendas e a música. Ali ele se reconhece nos elementos depreciados no entrecho da cultura hegemônica.

Se, no "lugar antropológico", os sujeitos fundamentam a posição social que ocupam, alicerçam suas personalidades mediante as referências compartilhadas, estabelecendo os limites que separam o "nós" dos outros, Ernesto, nas chicherías, buscava a partilha existencial com aqueles que sentia serem seus semelhantes. Porém, nunca encontrou os índios das fazendas da redondeza; apenas outros que ansiavam por liberdade e sentiam como ofensa a possibilidade de serem tolhidos pelo trabalho em terras alheias. Quanto à música, esta era fundamental para constituir a ambientação das chicherías e falava à alma de Ernesto: “(...) iba a laschicherías, por oírla música y a recordar. Acompañando en voz baja la melodía de las canciones, me recordaba de los campos y las piedras, de las plazas y los templos, de los pequeños ríos adonde fui feliz" (ARGUEDAS, 1991, p. 38). 
Geralmente retratando as relações do homem com a natureza das regiões de Apurímac e do Pachachaca, essas músicas conduziam os ouvintes às tíbias terras, onde se planta a cana-de-açúcar e as árvores frutíferas, com suas hostis formigas vermelhas e seus insetos vorazes. Assim, ao seu ritmo, desenham-se as cores e formas das planícies andinas, de modo que os acordes performam a sonoridade melancólica dos gélidos ventos e do anseio do homem - prisioneiro das amarras das condições socioeconômicas, climáticas e geográficas regionais - pela redenção histórica que poderia conduzi-lo à liberdade, tal qual a dos pássaros em alto voo.

¡Ay siwarken't! iAy picaflor!

Amaña waytatok'okachaychu,ya no horades tanto la flor

siwarken't. Alas de esmeralda.

Ama jhinakaychuNo seas cruel

mayupatamanurayamuspa, baja a la orilla del río,

k'oriraphra, Alas de esmeralda,

kaypukamayupiwak'ask'aytay mírame llorando junto al agua roja

k'awaykamuway. Mirame llorando.

(ARGUEDAS, 1993, p. 37).

Veja-se que Arguedas, em sua escritura, utiliza-se dos idiomas quêchua e espanhol, buscando figurar a realidade linguística peruana e romper com o distanciamento entre a palavra falada e a palavra escrita; égide sobre a qual se estruturou o que Angel Rama denomina como ciudad escrituraria, na obra Ciudad letrada (1998). De acordo com o autor, a cidade escriturária organiza-se por meio do estabelecimento de leis, classificações, regulamentos e normas, caracterizando um papel legislador e regulador da sociedade e dos espaços; normalização centrada na pretensa superioridade da cultura e do idioma europeus. Entretanto, esses signos reguladores não se comunicam diretamente 
com seus significantes, visto que a realidade é constituída pela diglossia no que se refere às línguas faladas e por confrontos ideológicos obscurecidos pelas práticas discursivas hegemônicas. Dessa maneira, elos linguísticos inimigos constituem a latino-américa: o elo urbano e o elo rural. Este era representado, especialmente, pelas línguas indígenas e africanas faladas por índios e negros que ocupavam os subúrbios, as pequenas aldeias e os campos. Nesse contexto, segundo Rama:

La literatura, al imponer la escritura y negar la oralidad, cancela el proceso productivo de ésta y lo fija bajo las formas de producción urbana. Introduce los interruptores del flujo que recortan la materia. Obviamente no hace desaparecer a la oralidad, ni siquiera dentro de las culturas rurales, pues la desculturación que la modernización introduce da paso a nuevas neoculturaciones, más fuertemente marcadas por las circunstancias históricas. Para éstas la ciudad letrada será ciega; también para el similar proceso que ocurre dentro de la misma ciudad, donde se prolonga la producción oral mezclándose con la escrita y dando lugar a nuevos lenguajes (...) (ARGUEDAS, 1993, p. 74).

Dessa forma, Arguedas adota, em Los ríos profundos, uma perspectiva que propõe desvelar os embates ideológicos materializados na realidade dentro do processo de modernização da sociedade peruana. Para isto, incorpora a postura do intelectual que representa "a utopia do Peru como nação quéchua moderna, capaz também de assumir e assimilar a riqueza da modernidade. Quase insensivelmente, o eu que buscava um mundo para poder ser, converte-se em um povo que para ser, para realizar sua identidade coletiva, tem de criar um novo mundo" (CORNEJO POLAR, 2008, p. 141).

A expressão desse novo mundo aparece configurada na composição da forma e do conteúdo de Los ríos profundos: na estruturação sintática, semântica e pragmática, na construção dos símbolos e das metáforas, na constituição das cronotopias' e na evocação 
memorialista. Assim, embora nessa análise não haja espaço para abordar todos esses aspectos, observa-se que todos eles testemunham o ethos problematizante da memória coletiva.

É, pois, segundo Pollak, em Memória e identidade social, mediante um conjunto de referências, signos e influências apreendidos pelos sujeitos nos contatos e confrontos relacionais que o desenho das identidades individuais e coletivas vai sendo traçado; desenho em que uma linha nova pode sempre ser acrescentada num processo nunca concluso. Desse modo, o encontro com outrem, as comparações, as identificações e os contrastes assumidos se elaboram na psique enquanto marcos designativos das idiossincrasias pessoais.

Sob esse prisma, o espaço do internato consolida-se como construção simbólica dos confrontos culturais e ideológicos da sociedade peruana. A sua construção física constituise de um primeiro pátio pavimentado, e outros de chão de terra, de paredes desnudas e úmidas e de velhos pilares de madeira que se espalham pelos corredores. É este um cenário em que se evidencia a intervenção das construções espanholas e que, para Ernesto, representam a interferência impositiva de uma arquitetura distante da históriamemória do Peru. Desse modo, a descrição arquitetônica do internato, sombria e esvaziada de vida, nos sentires do menino, contrapõe-se à do Muro Inca por ele visitado quando esteve em Cuzco na companhia do pai:

Caminé frente al muro, piedra tras piedra. Me alejaba unos pasos, lo contemplaba y volvía a acercarme. Toqué las piedras con mis manos; seguí la línea ondeante, imprevisible, como la de los ríos, en que se juntan los bloques de roca. En la oscura calle, en el silencio, el muro parecía vivo; sobre la palma de mis manos llameaba la juntura de las piedras que había tocado (ARGUEDAS, 1993, p. 5-6). 
La calle era lúcida, no rígida. Si no hubiera sido tan angosta, las piedras rectas se habrían quizá, desdibujado. Así estaban cerca; no bullían, no hablaban, no tenían la energía de las que jugaban en el muro del palacio de Inca Roca; era el muro quien imponía silencio; y si alguien hubiera cantado con hermosa voz, allí, las piedras habrían repetido con tono perfecto, idéntico, la música (ARGUEDAS, 1993, p. 10).

Vivas, as pedras personificadas ganham voz e relatam a história das etnias cuzqueñas e da liderança de Pachacútec que incita o início da expansão do Império Inca. Grafa-se, assim, a cultura, a tecnologia, a ciência e demais conhecimentos ancestrais de um povo que demarcou a história, a memória, a identidade coletiva da população peruana. Logo, nas intencionalidades apresentadas nos pressupostos e simbologias textuais, elaborados por Arguedas, estão envolvidas uma ação/reação sócio-história, de modo que não se está lidando somente com descrições imagéticas ou intencionalidades linguísticas, mas especialmente com os resultados provenientes dos relacionamentos interculturais, interdiscursivos e ideológicos.

Dessa maneira, a constituição do espaço do internato se funde aos ícones culturais europeus, figurando alegoricamente os embates sociais e religiosos do encontro entre tão distintas culturas. É então que o pátio escuro impõe medo, especialmente, nos internos menores. Isso ocorre, primeiramente, porque se configura como espaço de violência. Ali ora ou outra uma demente, ajudante da cozinha do internato, aparece e é abusada sexualmente por alguns dos internos maiores. Também ali os menores são coagidos e agredidos pelos mais velhos. Em segundo lugar, o pavor desse espaço é resultado do fato deum dos internos - de aproximadamente 20 anos, apelidado peluca, porque seu pai era barbeiro - ter lançado uma maldição aos demais meninos, acusando-os de anticristos. 
Considerava a si mesmo e a outro interno, chamado Lleras, os únicos cristãos verdadeiros.

Las palabras del "Peluca" definieron un antiguo presentimiento. Yo sabía que los rincones de ese patio, el ruido del agua que caía al canal de cemento, las yerbas pequeñas que crecían escondidas detrás de los cajones, el húmedo piso en que se recostaba la demente y donde algunos internos se revolvían, luego que ella se iba, o al día siguiente, o cualquier tarde; sabía que todo ese espacio oculto por los tabiques de madera era un espacio endemoniado. Su fetidez nos oprimía, se filtraba en nuestro sueño; y nosotros, los pequeños, luchábamos con ese pesado mal, temblábamos ante él, pretendíamos salvarnos, inútilmente, como los peces de los ríos, cuando caen en el agua turbia de los aluviones. La mañana nos iluminaba, nos liberaba; el gran sol alumbraba esplendorosamente, aun sobre las amarillas yerbas que crecían bajo el denso aire de los excusados. Pero el anochecer, con el viento, despertaba esa ave atroz que agitaba su ala en el patio interior (ARGUEDAS, 1993, p. 48).

Vê-se, pois, que o espaço aqui é personificado imageticamente pela palavra endemoniado. Entretanto, tal personificação ganha uma conotação completamente oposta a da prosopopeia da descrição das pedras. Aqui é dotada de uma atmosfera sombria, medonha e violenta, de modo que, como peixe em água turva de aluviões, Ernesto sente-se devorado, em seu ser, pela força opressora e agressora desse espaço icônico, que atrai magneticamente para ele, mas suga as energias e enche de terror aquele que ousa adentrar em suas esferas. Esse momento narrativo representa o ápice do sentimento de angústia provocado pela configuração espacial do internato. Tolhido em sua liberdade identitária pelo espaço, oprimido pelos colegas maiores e pelos símbolos da cultura do espanhol, resta-Ihe a memória como matéria ficcional que opera 
em busca das paisagens, espaços e personagens que atuaram em sua história como signos representativos da constituição do seu eu individual e social.

Portanto, a literatura, conforme afirma Raymond Williams, em Marxismo $e$ Literatura (1979), não pode ser vista como um mero objeto cultural, mas antes como prática social, pois se insere num amplo conjunto de valorações, produções e reproduções culturais. Assim, suas significações sócio-históricas são imprescindíveis para melhor compreensão da perspectiva do olhar de um povo, de seus modos de vida, de sua estrutura de sentimento e de pensamento, de seus confrontos socioideológicos e de seus anseios utópicos.

A arte, portanto, faz parte da construção do imaginário nacional e da identidade coletiva e é um elemento que não deve ser dissociado do processo constitutivo de sua memória histórica. Assim, a inter-relação entre os discursos histórico-culturais e ficcionais, imbricados nas formas artísticas, cumpre, essencialmente, uma função críticoreflexiva. E essa função liga-se ainda ao fato de que nas relações estabelecidas entre a história vivida das sociedades humanas e o esforço em descrevê-la, pensá-la e explicá-la conformam-se coerções e pressões, cujo eixo central tornou-se, em muitos momentos, a exclusão, de seu âmbito de sentido, de inúmeros homens que, em seu cotidiano, são atravessados por mecanismos de dominação e de opressão. Nessa perspectiva, a obra de José María Arguedas busca exatamente resgatar a voz desses homens.

\section{Referências}

ARGUEDAS, J. Los ríos profundos. Lima: Editorial Horizonte, 1993. 
AUGÉ, M. Não-lugares: introdução a uma antropologia da sobremodernidade. Tradução de Miguel Serras Pereira. Lisboa: 90 Graus Editora, 2005.

BAKHTIN, M. Questões de literatura e de estética: a teoria do romance. Tradução de Aurora Fornoni Bernardini, José Pereira Júnior, Augusto Góes Junior, Helena Spryndis Nazário e Homero Freitas de Andrade. São Paulo: Hucitec, 1988.

BACHELARD, G. A Água e os sonhos: ensaio sobre a Imaginação da matéria. São Paulo: Martins Fontes, 2002.

FILIPPO, T. Um diálogo entre "BalúnCanán" e "Los ríos profundos". 152 f. Tese (Doutorado em Letras). Universidade Federal Fluminense, Instituto de Letras. Niterói, 2008.

MOISÉS, M. Dicionário de termos literários. São Paulo: Cultrix, 2013.

CORNEJO POLAR, A. O condor voa. Belo Horizonte: UFMG, 2008.

POLLAK, M. Memória e identidade social. Estudos Históricos, Rio de Janeiro, v. 5, n. 10, 1992.

RAMA, A. Ciudad letrada. Montevideo: Arca, 1998.

\footnotetext{
'Em Questões de literatura e estética: a teoria do romance (1988), Bakhtin formula o conceito de cronotopo, em que aponta para o elo indissolúvel que há entre o tempo e o espaço, considerando o tempo como a quarta e física do espaço, visto que o tempo a percorre e torna-se perceptível mediante seu entrelaçamento ortogonal com as três dimensões espaciais. No espaço, a direção ortogonal percorre um ângulo reto que abrange as três dimensões observáveis: cima/baixo (altitude), norte/sul (longitude) e leste/oeste (latitude). Assim, juntos, tempo e espaço, representam uma categoria "conteudístico-formal" da construção narrativa.
}

Recebido em 19 de outubro de 2017.

Aceito em 21 de dezembro de 2017. 